\title{
Assessment of Knowledge, Attitude and Practices and the analysis of Risk Factors regarding Schistosomiasis Among Fishermen and Boatmen in Dongting Lake Basin, P.R. China
}

\section{Zhou Guan}

National Institute of parasitic diseases, Chinese Center for Disease Control and Prevention

\section{Si-Min Dai}

National Institute of Parasitic Diseases, Chinese Center for Disease Control and Prevention Jie Zhou

Hunan Institute of Schistosomiasis Control

\section{Xiao-Bing Ren}

Yueyang County Office for Preventive and Control on Schistosomiasis

\section{Zhi-Qiang Qin}

National Institute of Parasistic Diseases, Chinese Center for Disease Control and Prevention

Yin-Long Li

National Institute of Parasitic Diseases, Chinese Center for Disease Control and Prevention

Shan LV

National Institute of Parasitic Diseases, Chinese Center for Disease Control and Prevention

Shi-Zhu Li

National Institute of Parasistic Diseases, Chinese Center for Disease Control and Prevention

\section{Xiao-Nong Zhou}

National Institute of Parasitic Diseases, Chinese Center for Disease Control and Prevention

Jing Xu ( $\nabla$ xfmjing@163.com )

\section{Research}

Keywords: Schistosomiasis; Knowledge; Attitude; Practice; Prevalence; Influence factors; Logistic regression

Posted Date: December 27th, 2019

DOI: https://doi.org/10.21203/rs.2.18362/v2

License: (c) (i) This work is licensed under a Creative Commons Attribution 4.0 International License. Read Full License 
Version of Record: A version of this preprint was published at Parasites \& Vectors on June 1st, 2020. See the published version at https://doi.org/10.1186/s13071-020-04157-4. 


\section{Abstract}

Background: Fishermen and boatmen are a risk population for contracting schistosomiasis due to their high frequency of water contact in endemic areas of schistosomiasis in the People's Republic of China (P. R. China). To develop specific interventions towards this population, our present study was designed to assess the knowledge, attitudes and practices (KAPs) towards schistosomiasis of fishermen and boatmen, and to identify the risk factors associated with schistosome infection using molecular technique in the selected area. Methods: A cross sectional survey was conducted in the Dongting Lake Basin of Yueyang County, Hunan Province, P. R. China. A total of 601 fishermen and boatmen were interviewed from October to November in 2017. Information regarding socio-demographic details and knowledge, attitude, and practices toward schistosomiasis were collected using a standardized questionnaire. Fecal samples of participants were collected and tested by Polymerase Chain Reaction (PCR), and logistic regression analysis was conducted to explore the risk factors related to the positive results of PCR. Results: Of the 601 interviewed participants, over $90 \%$ of respondents knew of schistosomiasis and how the disease was contracted, the intermediate host of schistosomes and preventive methods. The majority of respondents had a positive attitude towards schistosomiasis prevention. However, only $6.66 \%$ (40/601) of respondents had installed a latrine on their boats, while $32.61 \%(196 / 601)$ of respondents defecated in the public toilets on shore. In addition, only $4.99 \%$ (30/601) respondents protected themselves while exposed to freshwater. The incidence of schistosomiasis, as determined by PCR, among fishermen and boatmen in Yueyang County was 13.81\% $(83 / 601)$. Age, years of performing the current job, number of times receiving treatment, and whether they were treated in recent three years were the main influencing factors of PCR results among this population.

Conclusions: Fishermen and boatmen are still at high risk of infection in China and gaps exist in knowledge, attitude and practices toward schistosomiasis in this population group. Chemotherapy, and health education encouraging behavior change in combination with other integrated approaches to decrease the transmission risk in environments should be improved.

\section{Introduction}

Schistosomiasis has been considered to be one of neglected tropical diseases of public health importance in tropical and subtropical areas of the world [1-3]. It is endemic in 78 countries and territories globally with 250 million people infected [4]. The People's Republic of China (P.R. China) used to have the highest disease burden of schistosomiasis caused by infection with Schistosoma japonicum. According to the national survey conducted in 1950s, there were estimated to be 11.60 million human cases and one million infected cattle [5]. Schistosomiasis is acquired when people or domestic animals contact freshwater contaminated with free swimming cercariae of schistosomes.

During the past seven decades, great efforts have been made to control schistosomiasis through consecutive and vertical control programs by the Chinese government. This is especially true over the past decade when preventing schistosomiasis ranked as a high priority among four important infectious diseases nationally, including HIV/AIDS, tuberculosis and hepatitis B [6]. During that time an integrated 
control strategy was also implemented for schistosomiasis according to the medium- and long-term national control plan [7-9]. The prevalence and intensity of infections with S. japonicum in humans has been reduced substantially, and the number of endemic provinces has decreased from 12 to seven [10, 11]. Currently schistosomiasis is mainly endemic in areas surrounding Dongting Lake, Poyang Lake and beaches along the Yangtze River [12-15], with fishermen, boatmen and farmers being groups at high risk of infection and suffering the highest disease burden [16].

In spite of the great success in schistosomiasis control in P.R. China as a result of these programs, there are still enormous difficulties and challenges surrounding transmission interruption and the elimination of schistosomiasis [17]. Potential risk factors for the resurgence of schistosomiasis still exists and the prevalence of schistosomiasis can rapidly rebound in the lake and marshland region due to its unique environment [18]. Tools used to determine the infection status or prevalence of schistosomiasis in humans are still heavily reliant on traditional methods, such as Kato-Katz, which presents the increasingly obvious disadvantage of poor sensitivity, especially in low endemic situations of mild infection $[19,20]$. The false negative result could eventually contribute to inappropriate decisions being made by the government. According to the national surveillance data, floating populations, and in particular, fishermen and boatmen, are becoming increasingly significant in schistosomiasis transmission [21]. Reinfection with $S$. japonicum among fishermen and boatmen is still a key issue impeding the transmission interruption or elimination of schistosomiasis in the lake and marshland regions in China [16].

Adequate knowledge, positive attitudes and the correct preventive practices of populations towards schistosomiasis prevention and control in endemic regions can provide an effective sustainable environment for the success and sustainability of schistosomiasis control [22-24]. Although health education is an important approach for schistosomiasis intervention, information on the current infection status and KAPs on schistosomiasis among fishermen and boatmen remains unclear. This study aimed to assess the KAPs towards schistosomiasis among fishermen and boatmen in selected areas. Infectious status and its influential factors were also identified in this population.

\section{Methods}

\section{Study Design}

This study was a cross-sectional survey that assessed the knowledge, attitude and practices (KAPs) on schistosomiasis, evaluated the prevalence of schistosomiasis and its risk factors among fishermen and boatmen in the study area.

\section{Study Area and Population}

The study was carried out from October to November in 2017 in Yueyang county, Hunan province, which is located on the eastern bank of Dongting Lake in southern China (Fig. 1). Two villages, Lujiao and 
Matang, in this county were sampled in random by stratified clustered sampling, in which the prevalence and villages were viewed as a stratum and clustering, respectively. As a typical lake and marshland endemic area of schistosomiasis, there were numerous fishermen and boatmen who were considered to be the most at-risk group of $S$. japonicum infection. Fishermen and boatmen in this region commonly live or work on ships for at least four months per year, and their economic income mainly comes from fishing and goods transportation. The study population was comprised of either the professional fishermen and boatmen, or the sidelines. All participants involved had not received any anti-schistosome treatment within a period of six months before the study. The interviews were conducted when their ships berthed in docking spots of Lujiao and Matang in Yueyang County, Hunan Province, P. R. China.

\section{Questionnaire Survey}

A pretested semi-structured questionnaire was developed after performing a thorough literature review of comparable studies [22, 25-28], to assess the KAPs of participants towards schistosomiasis prevention. This survey was conducted by well-trained interviewers and was monitored by quality control supervisors who were arranged for each group before the interviews. The questionnaire consisted of four main sections. The first part covered socio-demographic information such as age, gender, education, family income, water-contacting frequency, history of receiving schistosomiasis examination and treatment. The second chapter examined participants' knowledge of schistosomiasis, including the transmission season, susceptible population, definitive host, transmission mode, intermediate host, clinical manifestations, impacts on children and females, preventive methods, and anti-schistosome medication. The third component assessed participants' attitudes towards schistosomiasis prevention. The last section interviewed participants' practices on schistosomiasis prevention. The full questionnaire can be found in the online Supplementary Table S1.

\section{Prevalence Survey and Laboratory Investigations}

Feces from each participant were collected using a specific container, coded by unique identifiers and transferred to a laboratory in a local schistosomiasis control station. Each sample had two grams removed and placed in a cryopreservation tube at $-20^{\circ} \mathrm{C}$ for DNA extraction. After all the samples had been pretreated, DNA of $S$. japonicum was extracted from fecal specimens according to the steps of the DNA extraction kit (QIAGEN, Germany).

Genomic DNA extracted from fecal samples was subjected to PCR using 18S-FW (5'-TTCCG ATAAC GAACG AGAC-3') and 18S-RV (5'-AGCGA TAAAG CCACT ACAAC-3') specific primers amplifying a 469 bp region of the $S$. japonicum 18S-rRNA gene [29]. PCR was carried out in a final volume of $50.0 \mu \mathrm{l}$, containing: $2.0 \mu \mathrm{l}$ of template DNA, $25.0 \mu \mathrm{l}$ of dNTPs mix (TIANGEN BIOTECH Co., Ltd, BEIJING), $1.0 \mu \mathrm{l}$ of 
upstream and downstream primers, and $21.0 \mu \mathrm{l}$ of sterile double distilled water. The PCR conditions were as follows: 5 min at $94{ }^{\circ} \mathrm{C}$ (initial denaturation), 30 cycles of 20 s at $94{ }^{\circ} \mathrm{C}, 30 \mathrm{~s}$ at $56^{\circ} \mathrm{C}, 40 \mathrm{~s}$ at $72^{\circ} \mathrm{C}$, and finally $5 \mathrm{~min}$ at $72^{\circ} \mathrm{C}$ (final extension). Negative control (sterile double distilled water) and positive control (worm body tissues DNA) were set up in each batch of experiments. The PCR products were separated on $1.50 \%$ agarose gels. All of the positive PCR amplification products for 18s RNA were sequenced, and Blast comparison analyses were used to check the consistency with the targeted 18S-rRNA sequence.

\section{Data Management and Statistical Analysis}

Data collected were entered into a database using EpiData Version 3.0 and then analyzed using SAS Version 9.4 (Statistical Analysis System, RTI, Cary, North Carolina, USA). The analysis consisted of three parts. Firstly, descriptive statistics were used for the demographic characteristics of the respondents. Secondly, schistosomiasis control knowledge rates, positive attitude rates, and correct behavior rates were calculated in order to inform the KAPs of $S$. japonicum among study participants. Finally, the Schistosoma nucleic acid positive rate was calculated according to the results of PCR amplification and electrophoresis. Risk factors related to the positive results of PCR were analyzed by univariate logistic regression followed by stepwise regression and multivariate logistic regression model. $P$-values less than 0.05 were considered statistically significant.

\section{Results}

\section{Socio-Demographic Characteristics}

A total of 753 fishermen and boatmen were enrolled in this cross-sectional study. However, 122 people provided none or insufficient amounts of stool to prepare for PCR and 30 individuals had no or incomplete questionnaire data. Therefore, 601 individuals who completed the questionnaire and provided qualified stool samples were included in the final analysis. The socio-demographic characteristics of the respondents are presented in Table 1. The number of males was $345(57.40 \%)$ and females was 256 (42.60\%). The mean age of respondents was 50.04 years old (Standard Deviation, \pm 10.97$)$. A total of $59.90 \%(360 / 601)$ of respondents were sideline fishermen and boatmen, while $38.27 \%(230 / 601)$ were professional boatmen. The majority $(63.39 \%, 381 / 601)$ had been in their current jobs for 10 to 29 years, followed by those who have had their job for more than 30 years $(128 / 601,21.30 \%)$. Over $95 \%$ of respondents $(576 / 601)$ had received treatment against schistosomiasis at least once.

Participants' KAPs toward Schistosomiasis

Awareness of Schistosomiasis Knowledge 
Of the 601 respondents, $74.88 \%$ (450/601) knew that the susceptible season for infection with $S$. japonicum was from April to October and $72.05 \%$ (433/601) knew that all the populations were susceptible for infection of schistosomes. The majority $(95.67 \%, 575 / 601)$ of fishermen and boatmen mentioned snails as the intermediate host of $S$. japonicum while $75.04 \%(451 / 601)$ of them knew the final host of $S$. japonicum. Of those surveyed, $97.00 \%$ (583/601) mentioned contacting with $S$. japonicum-infested water was the way to get infection of schistosomes. In terms of their knowledge of the symptoms and effects of schistosomiasis, $86.69 \%$ (521/601) of study respondents mentioned fever and diarrhea to be the main symptoms of schistosomiasis, while $58.40 \%(351 / 601)$ knew that schistosomiasis would have severe impacts on females, and 62.7\% (377/601) indicated that schistosomiasis could limit children's physical growth. With respect to preventive activities and treatment for schistosomiasis, $96.17 \%$ (578/601) of interviewed fishermen and boatmen mentioned avoiding contact with S. japonicum-infested water as an effective preventive measure. Only $47.92 \%(288 / 601)$ of study participants mentioned praziquantel as an anti-schistosome drug (Table 2).

\section{Attitude to Schistosomiasis Prevention and Control}

Most respondents $(95.34 \%, 573 / 601)$ indicated that they were willing to install feces containers on their boats. Of the 28 participants who refused to install feces containers, $57.14 \%$ complained that fishing boats were too small to accommodate it. With regard to visiting onshore public toilets, $96.17 \%(578 / 601)$ reported that they would like to use onshore public toilets, while $72.7 \%$ of respondents who were reluctant to use onshore public toilets gave the reason that it was inconvenient to go ashore to find toilets over such a long distance when they were working in the middle of the lake. The majority of study respondents $(98.50 \%, 592 / 601)$ were willing to accept examination for schistosomiasis and if diagnosed as positives, $98.50 \%(592 / 601)$ of the study participants expressed a willingness to take medicine regularly following doctors' prescriptions. Of those surveyed, $89.85 \%$ (540/601) believed this disease could be prevented, while $71.88 \%$ (432/601) understood schistosomiasis could be cured (Table 3).

Practices of the Study Participants towards Schistosomiasis

Of the 601 respondents, only $6.66 \%$ installed and used fecal containers in the correct way. In terms of protective behaviors when contacting $S$. japonicum infested water, only $4.99 \%$ (30/601) of the respondents reported always wearing rubber shoes, gloves, protective clothing or ointment. Being too troublesome was the main reason mentioned by $83.98 \%$ (471/561) of those not always protecting themselves when contacting freshwater in Dongting Lake. Only $32.61 \%(196 / 601)$ of the participants reported always defecating in onshore public toilets (Table 3 ). 


\section{S. japonicum Infection Status and Related Risk Factors}

Among 601 participants who provided qualified stool samples, 13.81\% (83/601) were detected as positive by PCR. The PCR amplification products of all the positive samples were sequenced and the results showed that the DNA fragment was $469 \mathrm{bp}$, which was consistent with the target DNA both in length and sequence (Fig 2). The positive rate of Schistosoma nucleic acid in males (14.78\%) was higher than that of females $(12.50 \%)$, but no statistical difference was detected $\left(\chi^{2}=0.643 \llbracket p=0.423\right)$. The subgroup of participants who were aged less than 30 years old, performing their current job for more than 30 years, never been treated for schistosomiasis, or not received treatment during 2015-2017 presented the highest PCR positive rates of $38.10 \%(8 / 21), 21.09 \%(27 / 128), 32.00 \%(8 / 25)$ when conducting strata analysis (Table 4).

Based on univariate logistic regression analysis, nine independent variables were included in the multivariate logistic regression, including age, occupation, economic conditions, years of doing current job, infection history, diagnostic method, disease category, times received treatment, and whether received anti-schistosome treatment from 2015-2017.

The results of multivariate logistic regression analysis indicated that respondents aged 40-49, $50-59$ and $\geq 60$ years had significantly lower odds of being positive than younger groups ( $<30,30-39)$, as determined by PCR $\left(\mathrm{OR}_{40-49}=0.163,95 \% \mathrm{Cl}: 0.041-0.644 ; \mathrm{OR}_{50-59}=0.058,95 \% \mathrm{Cl}: 0.014-0.239 ; \mathrm{OR}_{\geq 60}=0.012,95 \% \mathrm{Cl}\right.$ : 0.002-0.065). The fishermen and boatmen who had performed their current job for 10 to 29 years and over 30 years were more likely to be PCR positives, with an $\mathrm{OR}_{10-29}=4.162(95 \% \mathrm{Cl}$ : 1.461-11.856), $\mathrm{OR}_{\geq 30}=18.684$ (95\%Cl: 5.430-64.295), respectively (Table 4). In addition, the respondents who received treatment six to 10 times, or more than 10 times showed lower odds of presenting positive PCR results $\left(\mathrm{OR}_{6-9}=0.156\right.$ (95\%Cl: $\left.0.035-0.689\right), \mathrm{OR}_{\geq 10}=0.100$ (95\% Cl: $\left.0.021-0.476\right)$ ), compared to those never receiving treatment for schistosomiasis. Respondents who received treatment from 2015 to 2017 were more likely to have negative PCR results (OR=0.479, 95\% Cl: 0.246-0.930) (Table 4).

\section{Discussion}

In this study, the KAPs survey was conducted to explore the level of KAPs of fishermen and boatmen on schistosomiasis in Yueyang County of Hunan Province, P. R. China. The infection status of schistosomiasis in this special group was determined by a sensitive method based on nucleic acid detection. The risk factors related to infection were identified through logistic regression models. This study aimed to provide information for the design and development of an integrated control strategy against schistosomiasis in China. 
The study showed that the overall awareness of schistosomiasis control knowledge among study participants was satisfactory, which was attributed to the persistent health education conducted for many years [30-32]. More than $90 \%$ respondents knew the cause of infection, intermediate host of schistosomes and preventive methods, while most of the respondents knew the disease, its clinical manifestations and transmission mode. However, less than $70 \%$ of respondents knew the medication against schistosomiasis or the disease impacts on children and females. It was also found that the majority of the respondents had positive attitudes towards schistosomiasis prevention. More than $95 \%$ of respondents were willing to install feces containers on their boats, use onshore public toilets, and take medicine against schistosomiasis, which would facilitate the control of schistosomiasis in this population. Nearly $90 \%$ of participants believed that schistosomiasis was preventable and $71.88 \%$ of respondents trusted that schistosomiasis could be cured.

Despite sufficient knowledge and good attitudes towards schistosomiasis prevention, the behavioral practices of fishermen and boatmen were quite unsatisfactory. People preferred to receive examinations and treatment, rather than prevent disease altogether. Only $6.66 \%$ of respondents had installed latrines on their boats and only $32.61 \%$ of respondents defecated in the onshore public toilets. There were many reasons for such findings given by the interviewed fishermen and boatmen, including the boat size and stools could overflow from containers because of boat instability, or that fecal odors could make such containers intolerable on board. Of the respondents, only $4.99 \%$ protected themselves when contacting freshwater, and the main concern of such respondents was that it was troublesome and inconvenient to wear protection apparatus when fishing or working on the water. Adequate knowledge and positive attitudes did not convert to effective behavior changes, mainly due to the strong economic drive of their work, which agreed with previous studies [22,33]. The gaps observed between knowledge, attitude and practices indicated that effective methods and enormous efforts should be made to better address the problem of transmission caused by behavior approaches. First, appropriate health promotion activities should be provided to this high risk population. Second, existing interventions should be improved or modified to be more accessible and attractive to fishermen and boatmen. Finally, integrated approaches to eliminate the transmission risk of schistosomiasis in freshwater areas should be further explored and strengthened [14]. The prohibition of fishing activities is going to be implemented along the Yangtze River, which can assist the current situation. An effective monitoring system needs to be established and run efficiently to guarantee this policy.

In P. R. China, a two-step detection pattern with serological screening first, followed by stool examinations for serological positives is used for the field diagnosis of schistosomiasis in China [16]. This method presented great advantages in earlier programs because of its enormous capacity for large scale screening and examination. However, with the persistent implementation of integrated control strategies for schistosomiasis, the prevalence and intensity of schistosomiasis in China has reached a historically low level [20,34]. The infected fishermen and boatmen can be easily misdiagnosed by traditional methods, such as the Kato-Katz method or miracidia hatching technique, and therefore, are not targeted for medication, which brings great challenge to the elimination of schistosomiasis in China [35, 36]. 
As a classic nucleic acid amplification technique, PCR has many advantages over stool examinations, such as higher sensitivity and specificity, the low cost of reagents, and the availability of universal equipment in laboratories, which will facilitate schistosomiasis detection in the future [37]. It was reported that only 2.16 eggs per gram of feces were required to detect schistosomiasis by PCR [37].

This study found a high burden of schistosomiasis in fishermen and boatmen in Yueyang County using PCR (13.81\%), which is higher than the average prevalence obtained from the national surveillance system[16, 22, 38]. The following considerations are therefore initiated for discussion. Firstly, the study population generally spend most of their lives onboard and are in frequent contact with $S$. japonicum infested water, which is thought to be the main reason for their vulnerability to infection and re-infection by schistosomes [36,39]. Secondly, interventions against schistosomiasis were not easy to cover all fishermen and boatmen due to their high mobility $[25,40]$. Among the 601 respondents in our research, $4.16 \%$ had never received treatment and $36.61 \%$ had only received treatment two years before our study. Thirdly, our study used a nucleic acid-based detection method rather than traditional methods. The PCR technique used in this article had an excellent sensitivity as it could detect $10 \mathrm{pg} / \mu \mathrm{l}$ of schistosome genomic DNA (based on internal assessments), as well as great specificity reflected by DNA sequencing of the PCR products. Therefore, PCR could facilitate the diagnosis and treatment of individuals with lowlevel infections and assist in the elimination of schistosomiasis in P. R. China.

Logistic regression analyses showed that four variables, including age, years of performing the current job, times received treatments in history, and whether received treatments in recent three years two years were significantly associated with the PCR results. Younger fishermen and boatmen are more likely to be infected by schistosomes, which is similar to results of previous research [25]. As the main labor forces of their families, young fishermen and boatmen are more likely to be involved in fishing or household chores, which means higher frequency and greater level of exposure to S. japonicum-infested water; therefore, increasing the likelihood for infection. In addition, there are also studies showing that aged fishermen and boatmen with long-term exposure to water can produce an acquired immunity towards Schistosoma, which protects them to a certain degree [6]. Using PCR, it was found that the number of years performing the current job was positively correlated with the infection of $S$. japonicum. Study findings showed that the prevalence decreased significantly with increasing treatment times among this population. The respondents who have never been treated and those who had only been treated one to five times presented positive rates of $32.00 \%$ and $17.13 \%$, respectively. Prevalence was higher in the participant subgroup that did not receive any treatment in the last two years. These results all indicated that PZQ treatment is still an effective way to control schistosomiasis among this population, so as to promote the elimination of schistosomiasis in P.R. China [26].

One of the limitations of this study is that 152 fishermen and boatmen were excluded from the final analysis due to incomplete response on the questionnaire or lack of stool samples for PCR test. This might has impact on the study's results. On the other side, such phenomenon reflected the difficulties of conducting control or prevention activities in low endemic areas after many years of intervention. To eliminate schistosomiasis, new approaches should be considered and explored how to improve the 
coverage rate of control activities on risk population and increase their compliance to ensure the effectiveness of intervention activities.

\section{Conclusions}

Our findings show that fishermen and boatmen remain the most vulnerable population for schistosome infection in endemic areas, and are an enormous obstacle in elimination of schistosomiasis in P. R. China. Among this population, younger fishermen and boatmen with longer occupational histories, as well as those with fewer treatments, particularly in the last three years, are at increased risk of acquiring infection. In addition, gaps exist in this population between knowledge, attitude and practices towards schistosomiasis prevention. Thus, it is suggested that enhanced medication, health promotion activities encouraging behavioral changes and other integrated approaches should be combined and strengthened to reduce the incidence of schistosomiasis amongst this high-risk population.

\section{Abbreviations}

P. R. China: People's Republic of China; KAPs: knowledge, attitude and practices; PCR: Polymerase Chain Reaction; NTDs: neglected tropical diseases; OR: odd ratio; 95\%Cl: 95\% confidence interval.

\section{Declarations}

\section{Ethics approval and consent to participate}

Ethical clearance had been granted by the Ethics Committee of the National Institute of Parasitic Diseases, Chinese Center for Disease Control and Prevention in Shanghai, P.R. China (20170717). During these meetings, the objectives of the study, the study procedures, sampling, study benefits, and potential risks and discomforts were orally explained and informed to all participants. All adult participants gave informed consent, and informed consent for all children who participated in the study was sought from parents or legal guardians. Assent was sought from all participants who were also informed of their rights to refuse to participate in this study and to withdraw from the study at any time. Participants with positive PCR results received free treatments with a standard dose of praziquantel.

\section{Consent for publication}

Not applicable.

\section{Availability of data and materials}

All relevant data are contained within the paper and its additional files.

\section{Competing interests}

The authors declare that they have no competing interests. 


\section{Funding}

This study was financially supported by the National Special Science and Technology Project for Major Infectious Diseases of China (No. 2018ZX10101002-002, 2012ZX10004-220) and The National Key Research and Development Program of China (2016YFC1202000).

\section{Authors' Contributions}

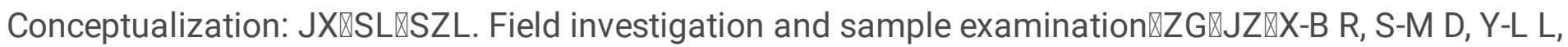
Z-Q Q. Supervision: JX, S-Z L, SL, X-N Z. Writing-original draft: ZG, S-M D, JX. Writing-review \& editing: JX. All authors read and approved the final manuscript.

Conceived and designed experiments: JX. Performed the experiments: ZG SMD. Analyzed the data: ZG. Wrote the paper: ZG SMD.

\section{Acknowledgments}

The authors would like to acknowledge the technicians of schistosomiasis control station of Yueyang County, who provided invaluable assistance with data collection and stool samples' collection. We are grateful to the schistosomiasis control institute of Hunan province, for permission and support.

\section{Authors' information}

\section{Affiliations}

National Institute of Parasitic Diseases, Chinese Center for Disease Control and Prevention; Key Laboratory of Parasite and Vector Biology, National Health Commission; WHO Collaborating Centre for Tropical Diseases; National Center for International Research on Tropical Diseases, Shanghai, People's Republic of China

Zhou Guan, Si-Min Dai, Zhi-Qiang Qin, Yin-Long Li, Shan Lv, Shi-Zhu Li, Xiao-Nong Zhou, Jing Xu* Hunan Institute of Schistosomiasis Control, Yueyang, People's Republic of China Jie Zhou

Yueyang County Office for Preventive and Control on Schistosomiasis, Yueyang, People's Republic of China

Xiao-Bing Ren

\section{References}

1. Bruun B, Aagaard-Hansen J. The Social Context of Schistosomiasis and Its Control: An Introduction and Annotated Bibliography. World Health Organization on be-half ofthe Special Programme for 
Research and Training in Tropical Diseases. 2008.

2. Steinmann, Peter, Keiser, Jennifer, Robert, Tanner, et al. Schistosomiasis and water resources development: systematic review, meta-analysis, and estimates of people at risk. Lancet Infectious Diseases. 2006;6(7):411-25.

3. Crompton DW. How much human helminthiasis is there in the world? Journal of Parasitology. 1999;85(3):397-403.

4. World Health Organization. Schistosomiasis: progress report 2001-2011 and strategic plan 20122020 2013. Available from: http://www.who.int/iris/bitstream/10665/78074/1/9789241503174_eng.pdf.

5. Zhou XN, Wang L-Y, Chen M-G, Wu X-H, Jiang Q-W, Chen X-Y, et al. The public health significance and control of schistosomiasis in China-then and now.2005; 96(2-3):0-105.

6. Xu JF, Xu J, Li SZ, Jia TW, Huang XB, Zhang HM, et al. Transmission Risks of Schistosomiasis Japonica: Extraction from Back-propagation Artificial Neural Network and Logistic Regression Model. PLoS Neglected Tropical Diseases,7,3(2013-3-21). 2013;7(3):e2123.

7. Wang LD, Chen HG, Guo JG, Zeng XJ, Hong XL, Xiong JJ, et al. A strategy to control transmission of Schistosoma japonicum in China. New England Journal of Medicine. 2009;360(2):121.

8. He JC, Wang TP, Zhang SQ, Gao FH, Zhang GH, Yang WP, et al. Evaluation of mid-term effectiveness of medium-and-long-term programme for prevention and control of schistosomiasis in Anhui Province. Chinese Journal of Schistosomiasis Control. 2011;23(3):249.

9. Zeng XJ, Chen HG, Hong XL, Hu ZH, Jiang WS, Hu SZ, et al. Evaluation on medium-term effect of schistosomiasis comprehensive control strategy based on infectious source control in Poyang Lake area. Chinese Journal of Schistosomiasis Control. 2012;24(4):382-6.

10. Zhou XN, Guo JG, Wu XH, Jiang QW, Zheng J, Dang H, et al. Epidemiology of schistosomiasis in the People's Republic of China, 2004. Emerging Infectious Diseases. 2007;13(10):1470.

11. Zhou XN, Wang LY, Chen MG, Wu XH, Jiang QW, Chen XY, et al. The public health significance and control of schistosomiasis in China--then and now. Acta Tropica. 2005;96(2-3):97.

12. Sun LP, Wang W, Zuo YP, Hong QB, Du GL, Ma YC, et al. A multidisciplinary, integrated approach for the elimination of schistosomiasis: a longitudinal study in a historically hyper-endemic region in the lower reaches of the Yangtze River, China from 2005 to 2014. Infectious diseases of poverty. 2017;6(1):56.

13. Colley DG, Bustinduy AL, Secor WE, King CH. Human schistosomiasis. Lancet.383(9936):2253-64.

14. Chitsulo L, Loverde P, Engels D. Focus: Schistosomiasis.2(1):12-3.

15. Abou-Zeid AHA, Abkar TA, Mohamed RO. Schistosomiasis and soil-transmitted helminths among an adult population in a war affected area, Southern Kordofan state, Sudan.5(1).

16. Guan Z, Lu S, Li SZ, Dang H, Zhang LJ, Xu J. Analysis on the situation of schistosome infections in floating population in national schistosomiasis surveillance sites of China. Zhongguo xue xi chong bing fang zhi za zhi = Chinese journal of schistosomiasis control. 2018;30(2):124-30. 
17. Zhou XN, Bergquist R, Leonardo L, Yang GJ, Yang K, Sudomo M, et al. Schistosomiasis japonica: control and research needs. Advances in Parasitology. 2009;72:145.

18. Zhao GM, Zhao Q, Jiang QW, Chen XY, Wang LY, Yuan HC. Surveillance for schistosomiasis japonica in China from 2000 to 2003. Acta Tropica. 2005;96(2-3):288-95.

19. Guan Z, Lu S, Li SZ, Xu J. Endemic status of schistosomiasis in floating population and control challenges in P.R. China. Zhongguo xue xi chong bing fang zhi za zhi $=$ Chinese journal of schistosomiasis control. 2017;35(6):598-603.

20. Xu J, Guan ZX, Zhao B, Wang YY, Cao Y, Zhang HQ, et al. DNA detection of Schistosoma japonicum: diagnostic validity of a LAMP assay for low-intensity infection and effects of chemotherapy in humans. PLoS neglected tropical diseases. 2015;9(4):e0003668.

21. Huang SY, Lin RX, Zhang QM, Deng ZH, Zhang XC, Huo LC. Analysis of schistosomiasis surveillance in floating population in Guangdong,2005-2009. South China Journal of Preventive Medicine. 2010.

22. Odiere MR, Rawago FO, Ombok... M. High prevalence of schistosomiasis in Mbita and its adjacent islands of Lake Victoria, western Kenya.5(1):278.

23. Norton AJ, Gower CM, Lamberton PHL, Webster BL, Lwambo NJS. Genetic Consequences of Mass Human Chemotherapy for Schistosoma mansoni: Population Structure Pre- and Post-Praziquantel Treatment in Tanzania.

24. Hotez PJ, Fenwick A. Schistosomiasis in Africa: An Emerging Tragedy in Our New Global Health Decade. Plos Neglected Tropical Diseases.3(9):e485.

25. Yu XL, Zhou J, He YK, Huang MZ, Li YS. Influence factors of Schistosoma japonicum infection among fishermen in eastern Dongting Lake Region. Chinese Journal of Parasitology \& Parasitic Diseases. 2013;31(4):307-9.

26. Zhang J, Li ZJ, Qiu L, Li D, Chen JJ, Xie H, et al. Development and application of communication materials for participatory health education of schistosomiasis in fishermen and boatmen of Poyang Lake region. Zhongguo xue xi chong bing fang zhi za zhi $=$ Chinese journal of schistosomiasis control. 2016;28(1):58-61.

27. Zhou J, Huang CY, He YK, Du YQ, Yu XL, Wang YY, et al. Epidemiological evaluation of schistosomiasis in migrant fishermen in Dongting Lake region. Chinese Journal of Schistosomiasis Control. 2010.

28. Cao CL, Bao ZP, Zhu HQ, Yu Q, Li SZ, Wang Q, et al. Analysis of schistosomiasis control requirements in boat fishermen in lake regions. Chinese Journal of Schistosomiasis Control. 2010.

29. Chen JH, Wen LY, Zhang XZ, Zhang JF, Yu LL, Hong LD. [Development of a PCR assay for detecting Schistosoma japonicum-infected Oncomelania hupensis]. Chinese Journal of Parasitology \& Parasitic Diseases. 2006;24(3):204.

30. Wang S, Carlton EJ, Chen L, Liu Y, Spear RC. Evaluation of an educational intervention on villagers' knowledge, attitude and behaviour regarding transmission of Schistosoma japonicum in Sichuan province, China. Acta Tropica.127(3):226-35. 
31. Zhou LY, Deng Y, Steinmann P, Yang K. The effects of health education on schistosomiasis japonica prevalence and relevant knowledge in the Peoplel"s Republic of China: A systematic review and meta-analysis. Parasitology International.62(2):150-6.

32. Hu GH, Jia H, Song K-Y, Lin D-D, Zhang J, Cao C-L, et al. The role of health education and health promotion in the control of schistosomiasis: experiences from a 12-year intervention study in the Poyang Lake area.96(2-3):0-241.

33. Cawston FG. Schistosomiasis in Southern Africa. 2010;127(6):509-13.

34. Zhou XN, Xu J, Chen HG, Wang TP, Huang XB, Lin DD, et al. Tools to support policy decisions related to treatment strategies and surveillance of Schistosomiasis japonica towards elimination. PLoS neglected tropical diseases. 2011;5(12):e1408.

35. Zhang LJ, Xu ZM, Qian YJ, Dang H, Lu S, Xu J, et al. Endemic status of schistosomiasis in People's Republic of China in 2015. Chinese Journal of Schistosomiasis Control. 2016;29(3):273.

36. Yi DH, Yi P, Liu ZC, Li YS, Quan MZ, Xiao SY. Practice and thought of schistosomiasis control with an emphasis on control sources of infection in Dongting Lake area. Chinese Journal of Schistosomiasis Control. 2009.

37. Pontes LA, Diasneto E, Rabello A. Detection by polymerase chain reaction of Schistosoma mansoni DNA in human serum and feces. American Journal of Tropical Medicine \& Hygiene. 2002;66(2):15762.

38. Malenganisho WLM, Magnussen P, Friis H, Siza J, Vennervald BJ. Schistosoma mansoni morbidity among adults in two villages along Lake Victoria shores in Mwanza District, Tanzania. Transactions of the Royal Society of Tropical Medicine \& Hygiene. 2008;102(6):532-41.

39. Ni L, Li PY, Mao XZ. Four predicaments facing Dongting Lake fishermen got ashore. Journal of Hunan Agricultural University. 2010.

40. Fabri RL, Florêncio JR, Pinto NDCC, Mattos ACA, Coelho PMZ, Vasconcelos EG, et al. Chromatographic Fingerprint Analysis and Effects of the Medicinal Plant Species Mitracarpus frigidus on Adult Schistosoma mansoni Worms. Biomed Research International. 2014;2014(8):941318.

\section{Tables}

\section{Table 1 Major socio-demographic characteristics of respondents attending KAPs survey and provided stool samples}




\begin{tabular}{llll}
\hline Variables & Category & Frequency & Percentage (\%) \\
\hline Gender & male & 345 & 57.40 \\
& female & 256 & 42.60 \\
\cline { 2 - 4 } Occupation & Professional fisherman & 11 & 1.83 \\
\cline { 2 - 4 } & Professional boatman & 230 & 38.27 \\
\cline { 2 - 4 } & sideline fisherman and boatman & 360 & 59.90 \\
\hline \multirow{2}{*}{ Age group } & $<30$ & 21 & 3.49 \\
\cline { 2 - 4 } & $30 \sim$ & 54 & 8.99 \\
& $40 \sim$ & 228 & 37.94 \\
& $50 \sim$ & 184 & 30.62 \\
\hline \multirow{2}{*}{ Education } & B0 & 114 & 18.97 \\
& Below primary school & 57 & 9.48 \\
\cline { 2 - 4 } & Primary school & 167 & 27.79 \\
\cline { 2 - 4 } & Junior middle school & 324 & 53.91 \\
\hline
\end{tabular}

Table 2 Knowledge of schistosomiasis among respondents

\begin{tabular}{lccc}
\hline Knowledge regarding schistosomiasis & Response & Frequency & $\begin{array}{c}\text { Percentage } \\
(\%)\end{array}$ \\
\hline Transmission season & & 450 & 74.88 \\
Susceptible population & Right & 151 & 25.12 \\
\hline Final host & Wrong & 433 & 72.05 \\
\cline { 2 - 4 } & Right & 168 & 27.95 \\
\hline Intermediate host & Wrong & 451 & 75.04 \\
\hline Cause of infection & Right & 150 & 24.96 \\
\hline & Wrong & 575 & 95.67 \\
\hline Main symptoms & Right & 26 & 4.33 \\
\hline Effects on children & Wrong & 583 & 97.00 \\
\hline Effects on women & Right & 18 & 3.00 \\
\hline Preventive measures & Wrong & 521 & 86.69 \\
\hline Medicine used for treatment & Right & 80 & 13.31 \\
\hline & Wrong & 377 & 62.73 \\
\hline
\end{tabular}


Table 3 Attitude and practices toward schistosomiasis prevention and control among the study participants

\begin{tabular}{llll}
\hline Attitude and practices toward schistosomiasis & Category & Frequency & \multicolumn{2}{l}{$\begin{array}{l}\text { Percentage } \\
\text { (\%) }\end{array}$} \\
\hline Willingness to install feces containers & Yes & 573 & 95.34 \\
Willingness to use onshore public toilets & No & 28 & 4.66 \\
\cline { 2 - 3 } & Yes & 578 & 96.17 \\
\hline Willingness to accept examination & No & 23 & 3.83 \\
\hline Willingness to take medicine & Yes & 592 & 98.50 \\
\cline { 2 - 4 } Belief that schistosomiasis could be prevented & No & 9 & 1.50 \\
\cline { 2 - 4 } & Yes & 592 & 98.50 \\
\hline Belief that schistosomiasis could be cured & No & 9 & 1.50 \\
\cline { 2 - 4 } & Yes & 540 & 89.85 \\
\hline Install and use fecal containers & Yes & 61 & 10.15 \\
\hline Defecate in public toilets onshore & No & 169 & 71.88 \\
\hline Protection when contacted water & Yes & 40 & 28.12 \\
& No & 561 & 9.66 \\
\hline
\end{tabular}

Table 4 Multiple logistic regression analysis of variables associated with $S$. japonica among study participants 


\begin{tabular}{lll}
\hline Risk factors & $\begin{array}{l}\text { Positive rate determined by PCR } \\
\text { (No. positives/No. examined) }\end{array}$ & \\
\hline $\begin{array}{l}\text { Age group (years) } \\
\quad 30\end{array}$ & $38.10 \%(8 / 21)$ & 1 \\
$30-39$ & $27.78 \%(15 / 54)$ & $0.318(0.075-1.354), P=0.1212$ \\
$40-49$ & $15.35 \%(35 / 228)$ & $0.163(0.041-0.644), P=0.0096 *$ \\
$50-59$ & $10.33 \%(19 / 203)$ & $0.058(0.014-0.239), P<.0001^{*}$ \\
$\geq 60$ & $5.26 \%(6 / 114)$ & $0.012(0.002-0.065), P<.0001^{*}$ \\
Years of doing current job & \\
$\quad<10$ & $7.61 \%(7 / 92)$ & 1 \\
$10-29$ & $12.86 \%(49 / 381)$ & $4.162(1.461-11.856), P=0.0076^{*}$ \\
$\geq 30$ & $21.09 \%(27 / 128)$ & $18.684(5.430-64.295), P<.0001^{*}$ \\
Treatment times & & 1 \\
0 & $32.00 \%(8 / 25)$ & $0.265(0.064-1.095), P=0.0666$ \\
$1-5$ & $17.13 \%(37 / 216)$ & $0.156(0.035-0.689), P=0.0142 *$ \\
$6-9$ & $12.26 \%(26 / 212)$ & $0.100(0.021-0.476), P=0.0038 *$ \\
$\geq 10$ & $8.11 \%(12 / 148)$ & 1
\end{tabular}

OR, odds ratio. CI, Confidence interval. *Significant association $(\mathrm{P}<0.05)$

\section{Supplementary File Legends}

Table S1 Questionnaire of socio-demographic data and KAPs for fishermen and boatmen

\section{Figures}




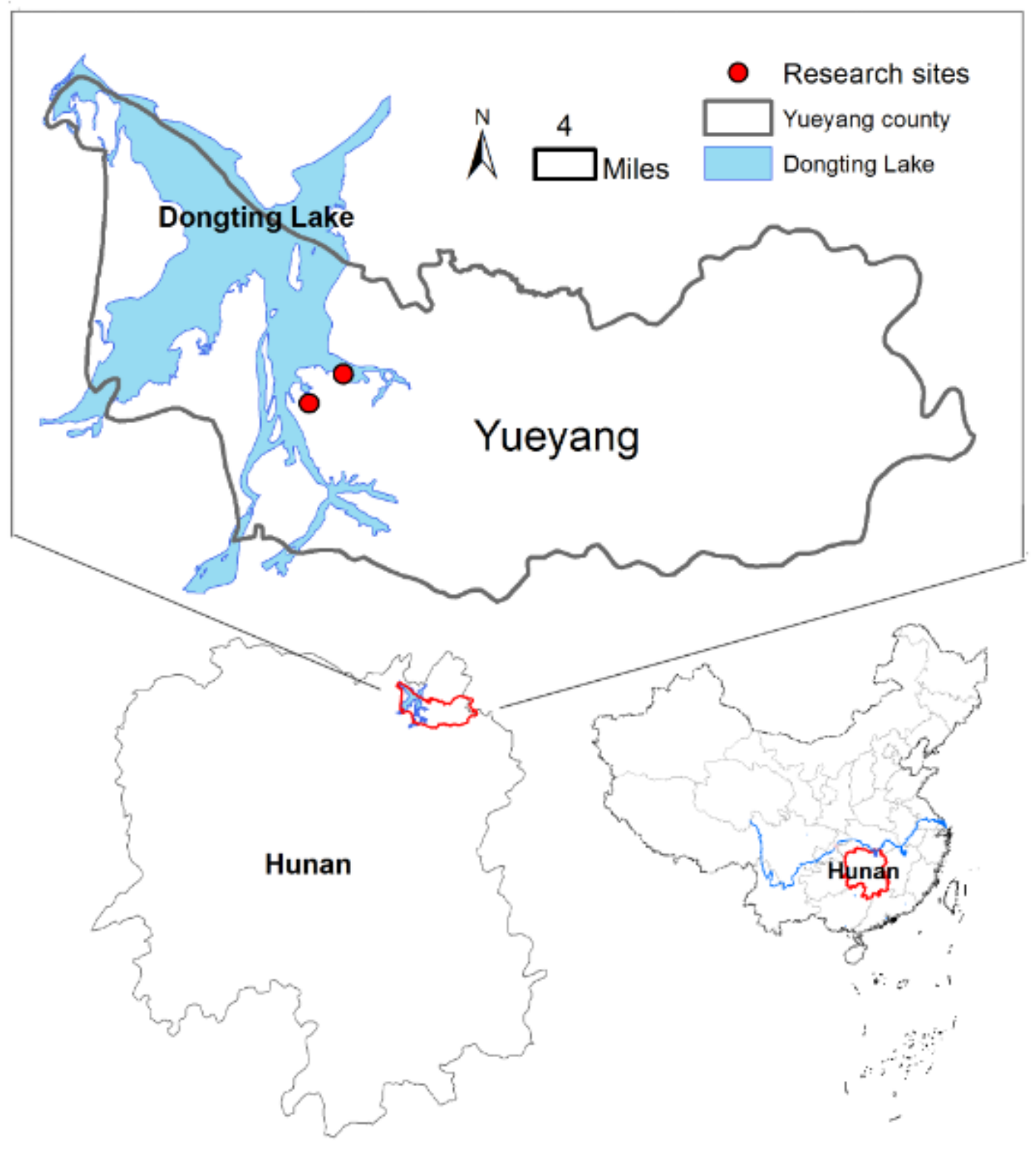

\section{Figure 1}

Location of Study Area in Yueyang County, Hunan Province. Note: The designations employed and the presentation of the material on this map do not imply the expression of any opinion whatsoever on the part of Research Square concerning the legal status of any country, territory, city or area or of its authorities, or concerning the delimitation of its frontiers or boundaries. This map has been provided by the authors. 


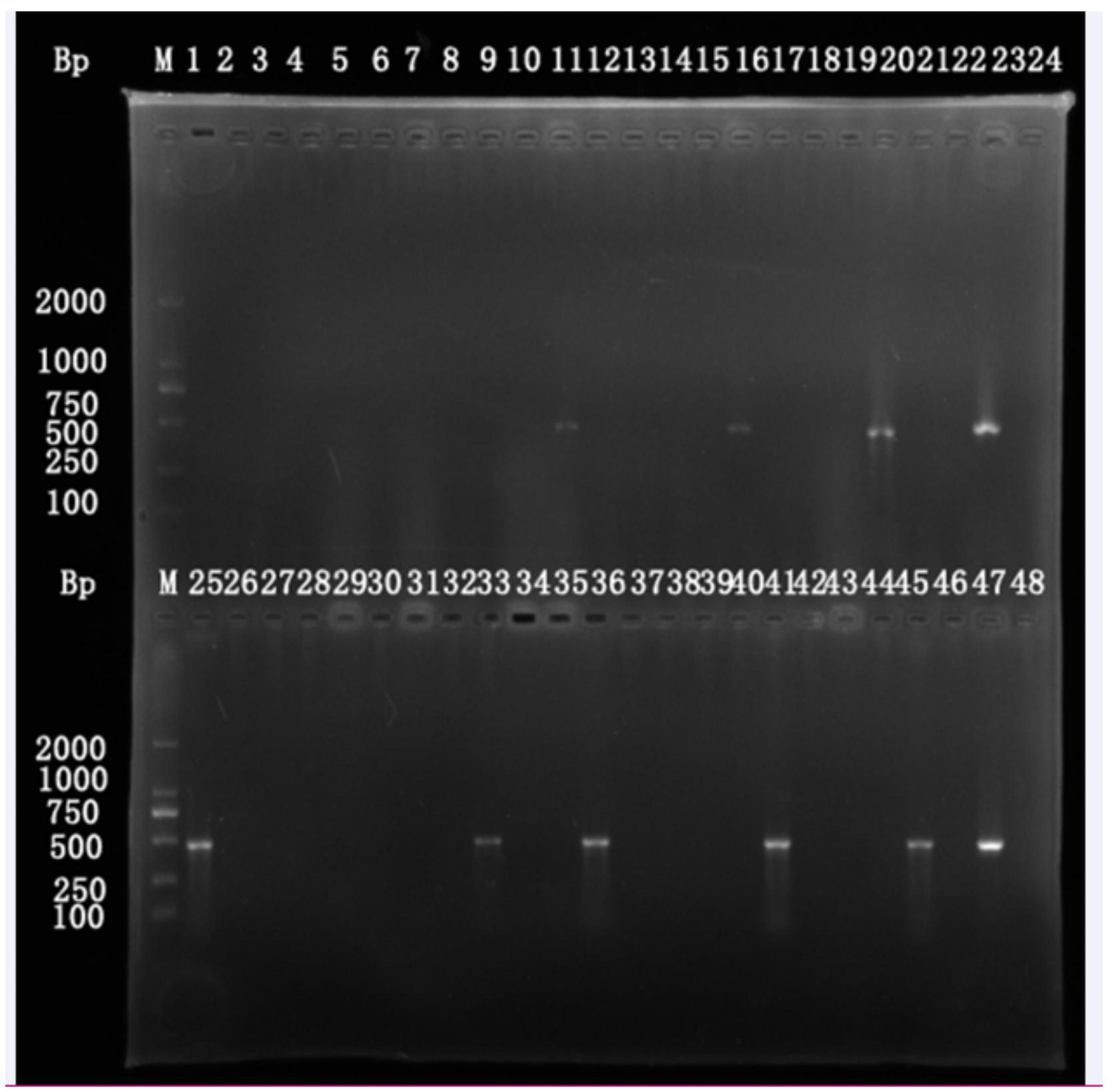

Figure 2

Results of PCR detection of the respondents

\section{Supplementary Files}

This is a list of supplementary files associated with this preprint. Click to download.

- TableS1Questionnaire.docx

- renamed8be02.jpg 